\title{
Fundamentals and Applications of Immunosensors
}

\author{
Carlos Moina and Gabriel Ybarra \\ Instituto Nacional de Tecnología Industrial, \\ Argentine Republic
}

\section{Introduction}

Immunosensors are compact analytical devices in which the event of formation of antigenantibody complexes is detected and converted, by means of a transducer, to an electrical signal, which can be processed, recorded and displayed. Different transducing mechanisms are employed in immunological biosensors, based on signal generation (such as an electrochemical or optical signal) or properties changes (such as mass changes) following the formation of antigen-antibody complexes. In this chapter, the basics of immunosensors are presented focused on the different transduction techniques used in immunosensing.

\section{The concept of biosensor: a convergence of biology, physical chemistry, and electronics}

Most clinical analysis are carried out by specialized staff in laboratories employing desk-top instruments, thus assuring the highest possible confidence in the obtained results. However, there are many cases in which a critical clinical analysis cannot be performed in those optimal conditions because of the lack of trained analysts or the required facilities, as is often the case in underdeveloped or isolated areas. In those cases, biosensors, which are compact analytical devices for the detection of specific analytes, can be the only option to make a trustworthy medical diagnosis. Especially immunosensors, a type of biosensors aimed at the detection of the presence of specific antibodies or antigens, are particularly important for the diagnosis of diseases in remote environments, where carrying out immunoassays such as ELISA (Enzyme-Linked Immunosorbent Assay) is not an option. The advantages of point of care (POC) testing versus laboratory testing can be summarized in the diagram introduced by von Lode (Fig. 1).

Although the possibility of carrying out in situ or point of care diagnosis with a minimum required training is a major reason for the development of biosensors in general and immunosensors in particular, there are many other reasons. For instance, fast, nonexpensive, multiple assays can ideally be performed with immunosensors and could be of help in epidemics to make proper diagnosis and follow the epidemic spreading.

In the rest of the chapter, we will present the basics of different types of immunosensors. We will begin considering the general outline of biosensors, which compromise three main components: a sensitive biological element, a transducer, and a signal processor. These three 


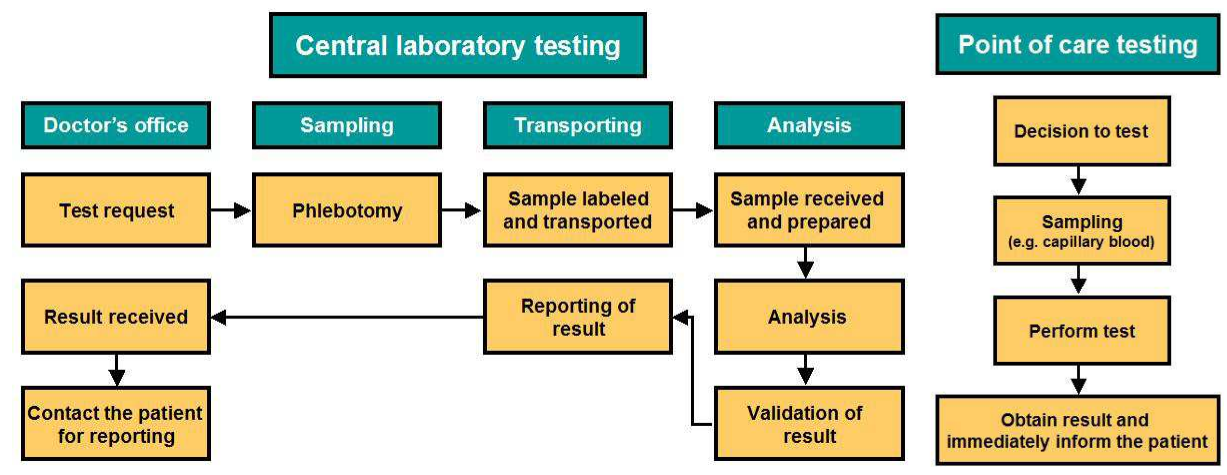

Fig. 1. Process of clinical testing in outpatient situations using central laboratory versus POC testing methods. The processes are shown in a simplified format and may sometimes contain additional steps (adapted from von Lode, 2005).

elements work together in integrated fashion as schematically shown in Fig. 2. The sensitive biological elements are usually biological materials such as enzymes, antibodies, cell receptors, nucleic acids, or microorganisms, although artificial biomimetic materials can also be employed. The sensitive biological element in the biosensors specifically recognizes the analyte in the sample generally via the formation of lock-and-key complexes: enzymesubstrate, antigen-antibody, and so on. The formed complex generates chemical signals or produces property changes, which are converted into an electrical signal by means of a transducer. There are several types of transducers and will be discussed with some detail in the rest of the chapter, the main ones being optical, electrochemical, and piezoelectric.

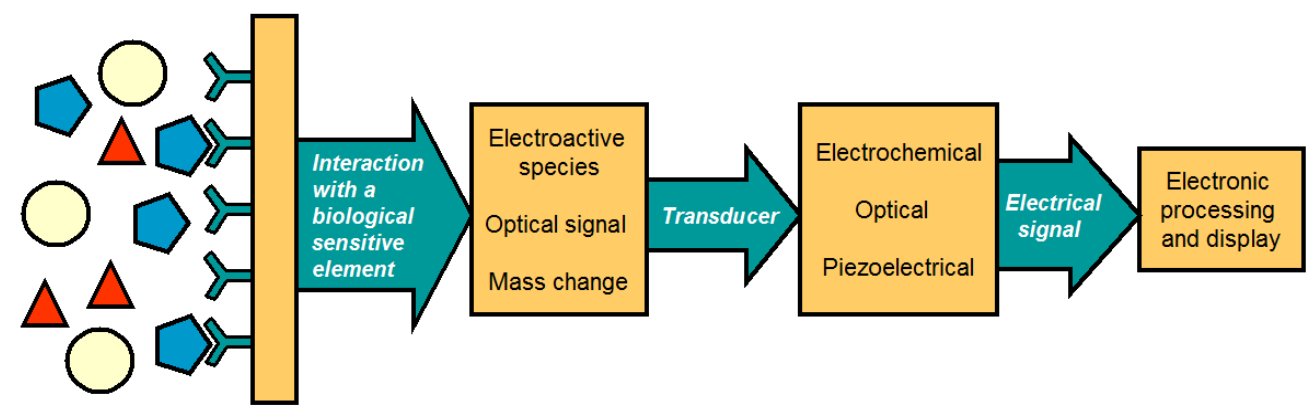

Fig. 2. Scheme of the basic integrated units that conform a biosensor.

Immunosensors make use of specific interactions between an antibody and an antigen. Antibodies are proteins generated by the immune system to identify bacteria, viruses, and parasites. The affinity between antibodies and antigens is very strong but of non-covalent nature. The development of sensitive and stable biological recognition elements is a key task in biosensors (Hock, 1997). However, biosensors, as a consequence of being highly integrated compact devices, are at a crossroad of different fields of knowledge. Biology and biotechnology are behind the key component of biosensors, as the sensitive biological elements provide the necessary specificity for the test. The generation of an electrical signal 
following the event of biological recognition involves the mastering of the transducing components, a field associated with chemical physics. Additionally, all these processes must be carried out at a small scale, with samples volumes in the order of microlitres, which requires the use of microfabricated structures and microelectronic circuits. Finally, biosensors can profit from the benefits of nanomaterials and nanostructures, such as large area to volume ratio, superparamagnetism, and surface enhanced resonance spectroscopy among many others, so nanotechnology has an increasing participation in the development of biosensors. Therefore, the biosensors field is by no means an exclusively biological field, but a truly multidisciplinary one.

\section{Recognition and transducing in immunological biosensors}

While biosensors can be used to detect many different analytes (not necessarily of biological nature as long as they interact specifically with the sensitive biological element), immunosensors are aimed mainly to the detection of the presence of certain antibodies or antigens in body fluids, especially in serum, although there is also a significant concern in the development of immunosensors employing antibodies for the detection of different analytes in diverse media, e.g. the quantification of TNT in groundwater via the formation of antibody-TNT complexes (Bromage et al., 2007). Therefore, the sensitive biological elements in immunosensors are antigens and antibodies (although in this chapter we will also include aptamers, which are single-stranded DNA molecules that work in fact as artificial antibodies forming aptamer-analyte complexes). Immunosensors can be designed for the detection of either antibodies or antigens; however, the detection of antibodies is preferred because the use of antibodies as sensitive biological elements may lead to a loss of affinity as a consequence of the immobilization of the antibodies onto a surface. Due to the high stability of the antigen-antibody complex once it is formed and the fact that the biological sensitive element is usually immobilized onto the surface of the transducer, most immunosensors are single use. Because some transducers are costly, there is a great concern in the regeneration of immunosensors, mainly by washing with an appropriate solution of high ionic strength or low $\mathrm{pH}$.

Signal transducing in immunosensors can be carried out by different means, taking advantage of different properties changes or signal generation, which occurs following the formation of antigen-antibody complex. Although there are many kinds of transducers, this chapter is concerned with biosensors where the transducing mechanisms are related to the measurement of electrons, photons, and masses. Other mechanisms of transduction include thermal changes and $\mathrm{pH}$ variation. Therefore, the main transducers employed in immunosensors that this chapter will deal can be summarized as follows:

- Electrochemical transducers. In this case, an electrical signal is measured, which shows significant differences in magnitude if antigen-antibody complex are formed. The main electrochemical transducers are amperometric (measuring of current), potentiometric (measuring of electrode potential or voltage differences) and conductimetric (measuring of conductivity or resistance).

- Optical transducers. In this case, either an optical signal is generated (e.g. color or fluorescence) or a change in the optical properties of the surroundings following the antigen-antibody complex formation is measured. 
- Piezoelectric transducers. The formation of antigen-antibody complexes implies an increase of mass as compared with the antigen or the antibody alone that is detected with piezoelectric devices, such as a quartz crystal balance or a cantilever.

In the following sections, these transducing mechanisms will be reviewed with selected examples from the literature.

\section{Electrochemical immunosensors}

In electrochemical immunosensors, the event of the formation of antigen-antibody complex is converted into an electrical signal: an electric current (amperometric immunosensors), a voltage difference (potentiometric immunosensors), or a resistivity change (conductimetric immunosensors).

The most common type of amperometric immunosensors can be regarded as ELISA tests with electrochemical detection, where redox species generated by a redox enzyme (enzymatic label) are converted into a measurable current. The aim of the test is to detect the presence of antibodies in serum via the formation of antigen-antibody complexes. An usual strategy is to immobilize the antigen onto the surface of a conductive electrode such as gold through adequate molecular linkers, for instance amino or carboxylic acid thiols. Thiols strongly bond to the gold surface, forming a self-assembled monolayer and providing the amino or carboxylic groups at the end of a small hydrocarbonated chain to which proteins can be covalently bonded. During an incubation time (typically from 30 to 60 minutes) with a positive serum, antigen-antibody complexes are formed. After rinsing, a second incubation is carried out with a solution containing anti-human Ig antibodies labeled with a redox enzyme, such as horseradish peroxidase (HRP). The formation of the antigen-antibodylabeled antibody complex is detected after the addition of the enzyme substrate and a proper redox mediator (cofactor). In the case of HRP, the substrate is hydrogen peroxidase and the redox mediator must be an adequate electron donor (a reduced species such as hydroquinone). HRP enzymatic activity converts the reduced redox mediator (hydroquinone) into an oxidized one (benzoquinone), which is further electrochemically reduced at the electrode surface. Thus, a steady-state current is established in a process schematically shown in Fig. 3. For negative sera, no antigen-antibody-enzyme labeled antibody complexes are formed in the first place so that the measured current values are considerably lower. Thus, high current values are indicative of a positive result.

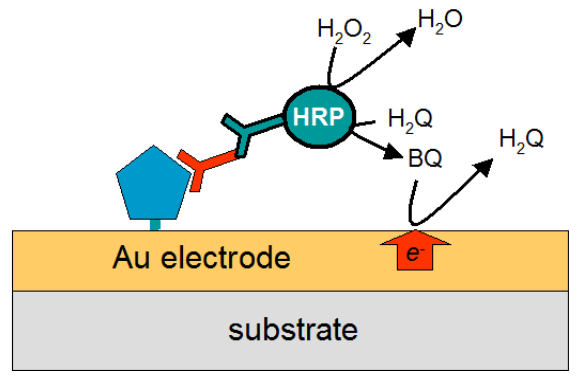

Fig. 3. Schematic representation of the electrochemical detection of enzyme-linked immunoassay with antigens immobilized onto a gold electrode (adapted from Longinotti et al., 2010a). 
In order for the immunosensor to work properly, it is necessary that the enzyme employed as a label must be close to the electrode surface. If the antigen is immobilized onto the electrode surface, this requisite is complied. The immobilization of the biological recognition element onto the surface of the transducer is by far the most common configuration employed in biosensors. Nevertheless, it is possible to devise different immobilization carriers, such as magnetic beads, which can be placed onto the electrode surface by applying magnetic fields. Antigens can be immobilized onto the surface of the magnetic beads. The formation of antigen-antibody is more efficient and faster when using nanoparticles with respect to direct electrode immobilization. As a consequence, the incubation time has been reduced to a few minutes (Melli, 2011). After incubation, the magnetic beads can be placed onto the electrode surface by means of a magnet and removed once the test has been completed (Fig. 4). This strategy also allows the electrodes to be re-utilized several times.

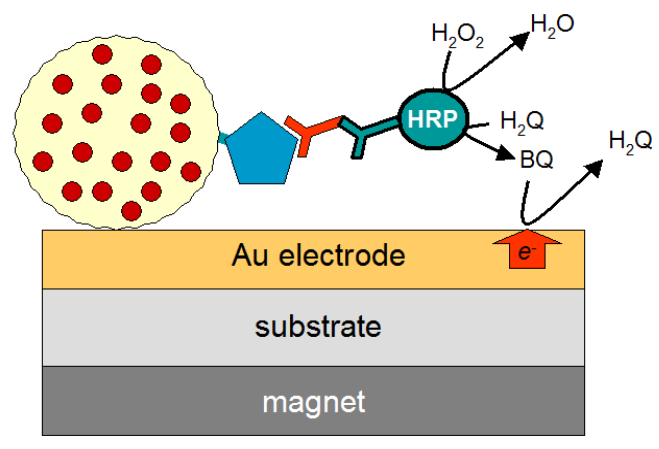

Fig. 4. Schematic representation of the electrochemical detection of enzyme-linked immunoassay with antigens immobilized onto silica-coated iron oxide nanoparticles (adapted from Longinotti et al., 2010b).

A promising type of immunosensors with electrochemical detection employs aptamers as the sensitive biological element. Aptamers are synthetic, single-stranded DNA molecules, which specifically bond to molecular targets, such as proteins and haptens, and can be regarded as synthetic antibodies. An interesting aspect of using aptamers as the recognition element in place of proteic antibodies is that it makes possible label-free biosensors. Plaxco et al. have been pioneering the development of such biosensors, which has been proved effective for the recognition of thrombin by electrochemical methods (aptamers have been previously used for the detection of thrombin in optical biosensors). In this type of biosensors, the single-stranded DNA that forms the aptamer is immobilized onto an electrode surface from one end and linked to a redox label from the other end. The event of formation of aptamer-target molecule complex leads either to an activation or to a deactivation of the redox probe (Fig. 5). In both cases, the change in redox activity can be measured as a current, usually employing a highly sensitive electrochemical technique such as AC voltammetry.

Field-effect transistors (FET), which have found wide application in ion sensing (i.e. ionselective field-effect transistors, ISFETs), can also be employed in biosensors, and open a very promising field. Briefly, a FET consists of three terminals, called gate, drain, and source. The gate controls the current between the source and the drain and, what is most important in 


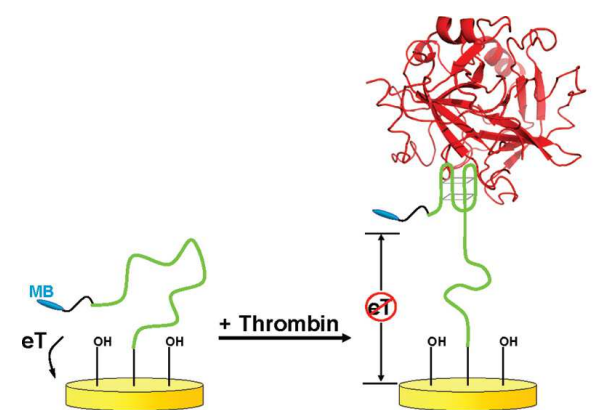

(a)

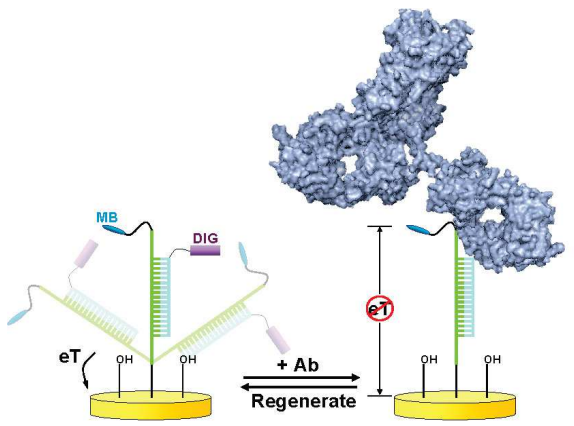

(b)

Fig. 5. (a) An electrochemical, aptamer-based sensor comprises a redox-tagged DNA aptamer directed against the bloodclotting enzyme thrombin. Thrombin binding reduces the current from the redox tag, readily signaling the presence of the target (Xiao et al., 2006). (b) Utilizing double-stranded DNA as a support scaffold for a small molecule receptor, sensors for the detection of protein-small-molecule interactions have been fabricated, for instance, for the detection of low nanomolar concentrations of antibodies against the drug digoxigenin (Cash et al., 2009).

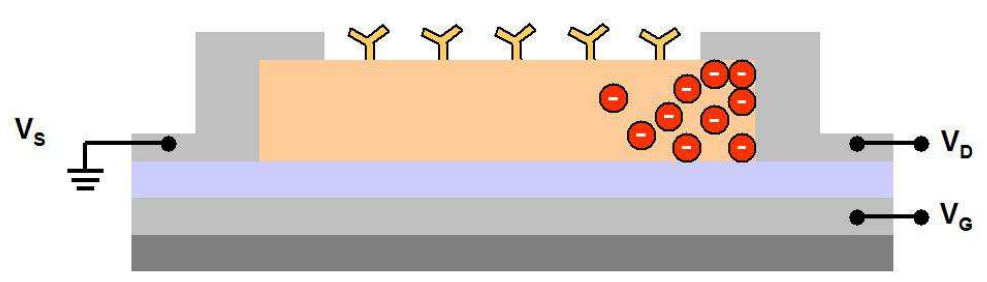

Before recognition

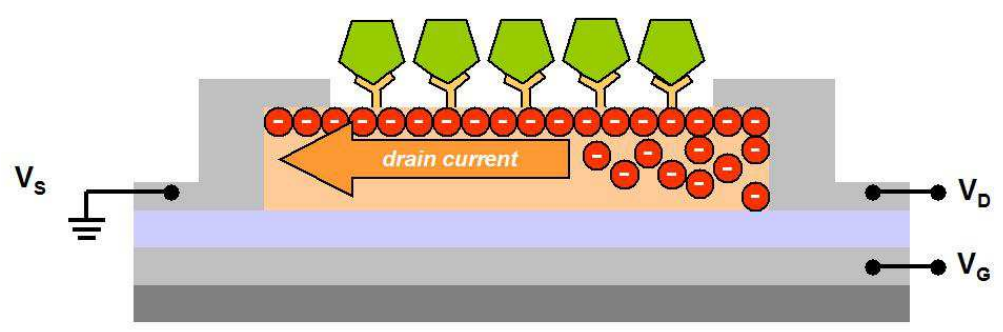

After recognition

Fig. 6. Schematic of a FET immunosensor. The formation of antigen-antibody complex at the gate terminal modulates the charge carrier flow between source and gate, generating an increase in current (adapted from Ivanoff Reyes et al., 2011). 
sensors applications, can be made sensitive to particular substances. For instance, in the scheme shown in Fig. 6, biofunctionalization of gate with antibodies enables the exposed channel direct interaction with the antigens detected. The formation of antibody-antigen complex causes the majority carriers of the n-type channel to accumulate and facilitate a conduction path for the charge carriers' flow from drain to source. It is a compact, label-free immunosensor in which an electrical signal is generated as a consequence of the formation of the antibody-antigen complex. Of course, FET biosensors are compatible with microelectronics technology, which allows a high degree of integration between all components of the biosensors: detection, transducing, and signal processing.

\section{Optical immunosensors}

In optical biosensors, the biological sensitive element is immobilized onto the surface of the transducer and respond to the interaction with the target analyte either by generating an optical signal, such as fluorescence, or by undergoing changes in optical properties, such as absorption, reflectance, emission, refractive index, and optical path. The optical signals are collected by a photodector and converted into electrical signals that are further electronically processed. There are many reviews on optical biosensors, the one by Borisov \& Wolfbeis, 2008, is highly recommended. The main optical phenomena employed in optical immunosensors are summarized in Table 1.

\begin{tabular}{ll} 
Optical Signal & Transducing technique \\
\hline Absorbance & Light intensity measurement \\
Reflectance & Light intensity measurement \\
Fluorescence & Total internal reflection fluorescence \\
Refraction index & Interferometry \\
& Surface plasmon resonance (SPR) \\
& Total internal reflection \\
Optical path & Interferometry \\
Spectroscopies & Surface enhanced Raman scattering (SERS) \\
\hline
\end{tabular}

Table 1. Main optical phenomena employed in optical immunosensors.

The geometric design of optical platforms is a key point to achieve efficient and integrated optical immunosensors. There are several geometric layouts, the most usual being strips, waveguide fibers (Leung et al., 2007), planar optical waveguide systems, capillary sensors, and arrays. Planar waveguide systems are especially attractive because of the possibility of innovative designs and the integration of multiple functionalities onto a single sensor. Planar geometry is compatible with microfabrication technologies and can be integrated with microfluidic systems (lab-on-a-chip). These attributes have made planar waveguides an ideal platform for development of integrated optical sensors. Several optical transducing techniques can be employed in planar waveguide systems: interferometry, surface plasmon resonance, and light-coupling strategies to transduce refractive index changes. Planar waveguide platforms comprise a planar substrate made of glass, plastic, or silicon that forms the basis of the sensor platform (Yimit et al., 2005). In some cases, this substrate acts as the waveguide, while in others an additional waveguide layer is deposited onto the substrate. All examples given in this section are considered for a planar configuration. 


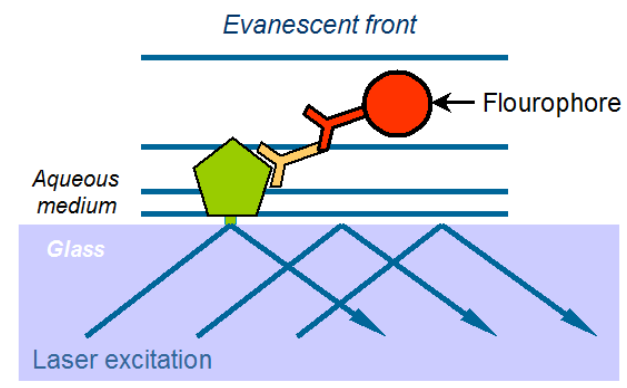

Fig. 7. Principle of the total internal reflection fluorescence. On reflection at dielectric interface, light penetrates into the second phase that has a lower refractive index than that of the core. Intensity decreases exponentially over the penetration (which typically is about as long as the wavelength of the light employed). Any labeled antibodies located close to the glass-aqueous medium interface are excited to produce fluorescence, while those located further into the solution will not.

Fluorescence is one the most widely methods employed in immunosensors, especially in ELISA-like immunosensors where the conjugate antibody is labeled with a fluorescent probe. Using an evanescent wave spectroscopic technique, such as total internal reflection fluorescence, can enhance the sensitivity of the biosensor. When light is transported by total internal reflection in an optical guide, an evanescent field is generated at the interface between the guide and the external medium. The penetration depth of this exponential field is of the order of the incident wavelength. Therefore, if the optical guide is placed in contact with a solution containing fluorophores, only those within the evanescent field are excited by light. In this way, fluorescent labels can be employed in conjunction with total internal reflection in ELISA-like immunosensors as schematically shown in Fig. 7. Unbound labeled species in solution remain unexcited and do not contribute to the background signal. An additional advantage of total internal reflection fluorescence measurements is that it can be performed in absorbing or turbid media.

The measurement of changes in the refractive index that takes place at the interface between the guide and the external medium is the basis for optical transducing techniques employed in refractometric immunosensors (Fig. 8). Surface plasmon resonance is one of the main optical biosensor technologies and has been the subject of numerous reviews (Mullett et al., 2000; Homola, 2003; Scaranoa et al., 2010).

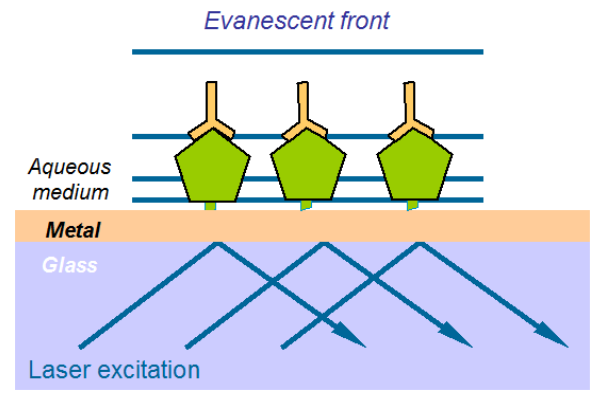

Fig. 8. Schematic representation of the surface plasmon resonance immunosensor. 
Many refractometric immunosensors are based on interferometric techniques. The MachZehnder interferometer is one of the most commonly employed interferometers in immunosensors (Fig. 9). In the Mach-Zehnder interferometer, the optical power is transported by a single-input waveguide, which is split equally between two parallel waveguides and recombined by means of two Y-splitters. When used in immunosensors, both branches are coated with the biological sensitive element (antigen or antibody). One of the waveguides is exposed to the sensing environment while the other branch serves as a reference waveguide. Changes in the refractive index of the sensing layer environment influence the effective refractive index in the sensing channel, which induces a phase shift in the optical signal that propagates through this channel. Upon recombination, interference of the two optical signals occurs and the measured output power changes depending on the phase shift between these two signals.

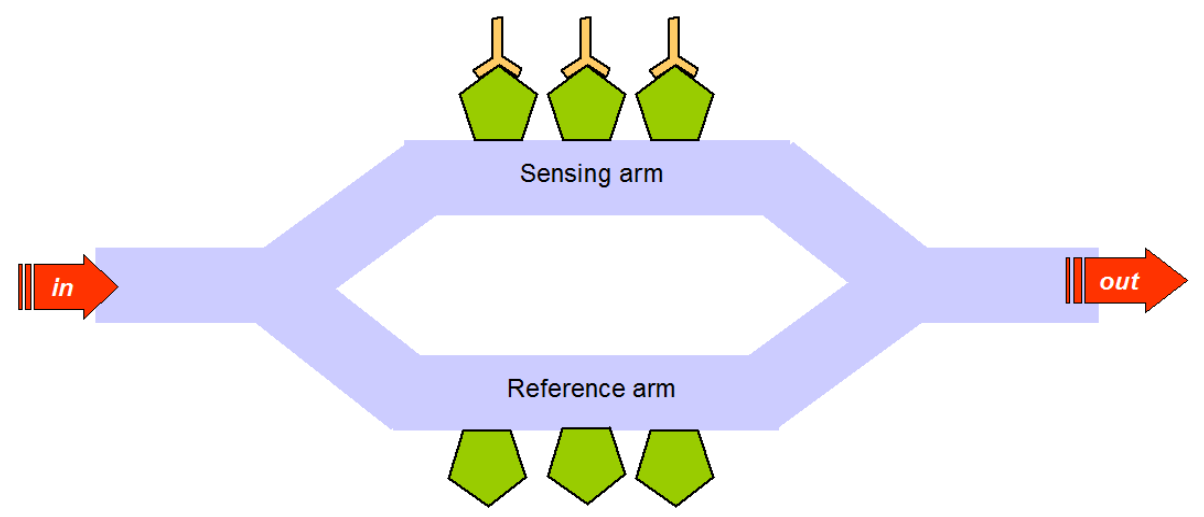

Fig. 9. Schematic of a Mach-Zehnder interferometer used for immunosensing.

Other interferometric immunosensors are based on changes in optical path rather than in the refractive index. Changes in the thickness of the thin film deposited on a substrate due to swelling upon interaction with the analyte of interest can be detected as shifts in the interference pattern.

\section{Piezoelectric immunosensors}

The mass changes that take place after the formation of antigen-antibody formation can be measured by means of piezoelectric transducers, such as quartz crystal microbalances and microcantilevers, which vibrate at a certain frequency sensitive. Antigens or antibodies can be immobilized onto the surface of piezoelectric devices and the formation of the antigenantibody complex can be detected as a vibration frequency shift with a high sensitivity (Janshoff et al., 2000; Raiteri et al., 2001).

Microcantilevers are especially attractive for immunosensors because of the possibility of microfabrication at low cost. Microcantilevers can also be employed in a static, nonvibrating mode, detecting the event of formation of antigen-antibody complexes via the deflection of the cantilever as a result of the surface stress it provokes (Fig. 10). 

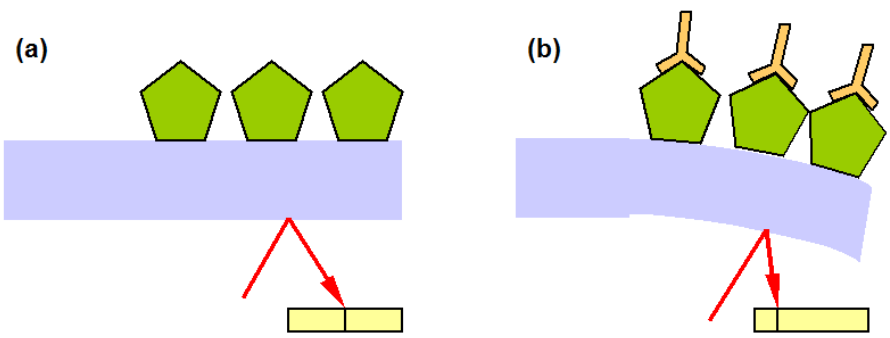

Fig. 10. Microcantilever working in static mode. The formation of the antigen-antibody complexes provokes a surface stress and, consequently, a deflection of microcantilever, which is detected optically.

\section{Analyte}

Escherichia coli O157:H7
Transducing technique

References

Tokarskyy \& Marshall, 2008

Surface plasmon resonance

Piezoelectric

Electrochemical

Fluorescence
Fratamico et al., 1998

Su \& Li, Y. 2004

Radke \& Alocilja, 2005

Yu et al., 2002

\section{Antibodies}

Antibody aimed at foot-andmouth disease

Various antibodies aimed at Chagas disease

\section{Tumoral markers}

Prostate-specific antigen (PSA) PSA

PSA, C-reactive protein

PSA, PSA- $\alpha 1$-antichymotrypsin, CEA, mucin-1

CA 125, CA 153, CA 199, CEA
Electrochemical

Longinotti et al., 2010

Electrochemical and fluorescence

Melli, 2011

Chen et al., 2009

Meyerhoff et al., 1995

Rusling et al., 2009

Wee et al., 2005

Zheng et al., 2005

Fu et al. 2007

\section{Toxins and pollutants}
Aflatoxins
Electrochemical
Owino et al., 2007
TNT
Fluorescence
Bromage et al., 2007
Clostridium botulinum toxin A
Fluorescence
Ogert et al., 1992

Table 2. Some examples of analytes detected with immunosensors and immunoassays. 


\section{Prospects and future of immunosensors}

Immunosensors have been used for the detection of pathogens, antibodies, toxins, biomarkers, among other analytes (Table 2). The wide spectrum of application of immunosensors ascertains a great future for this type of biosensors. Especially attractive is the possibility of carrying out point of care testing (Skottrup et al., 2008), as discussed previously in the introduction. Although all transducing techniques have advantages and disadvantages, much of the success of immunosensors in point of care testing depends on the intrinsic detection limits, the required sample preparation (e.g. the possibility of direct detection of the analyte), and the degree of integration of the units that conforms a biosensor. All these crucial aspects are conditioned by the type of transducer employed in immunosensors. For instance, the limit of detection of fluorescence is eventually a single molecule (Table 3), but fluorescence transduction in immunosensor usually requires a fluorescent label, and a rather complex optical instrumentation that compromises a high degree of integration among the biological sensitive element, the transducer and the electronic instrumentation. It is in this sense that field-effect transistors seem to be the optimal transducers, because they do not require a label and the biological sensitive element is immobilized onto the surface of the transducer that itself forms part of the electronic instrumentation.

\begin{tabular}{lcl} 
Technique & $\begin{array}{c}\text { Limit of detection } \\
\left(\mathbf{m o l e c u l e s ~} \text { per } \mathbf{~ m}^{\mathbf{2}}\right)\end{array}$ & References \\
\hline Fluorescence & 1 & \\
Hollow cantilevers & 10 & Burg et al., 2007 \\
Surface plasmon resonance & $10^{2}$ & Myszka, 2004 \\
Quartz crystal balance & $10^{3}$ & \\
Microcantilevers & $10^{6}$ & Braun et al., 2005 \\
\hline
\end{tabular}

Table 3. Estimated order of magnitude of the limits of detection for different transducing techniques.

A diagram with a comparison of the compromise between the ease of integration and the ease of sample preparation for the different transducing techniques is presented in Fig. 11.

The future of biosensors will be greatly influenced by the inclusion of nanomateriales, which provide new tools to improve the performance of immunosensors (Chen et al., 2009). There is a great interest in including carbon nanotubes in biosensing (Jacobs et al., 2010), taking advantage of their conductive properties. Also nanoparticles can provide new strategies for immunosensors design, and especial interest is in the use of quantum dots in optical transducers, with a higher fluorescence efficiency. Superparamagnetic nanoparticles are also been increasingly used in biosensing (Longinotti et al., 2008; Lloret et al., 2010). A point of care testing device aimed at the diagnosis of foot-and-mouth disease, brucellosis, and Chagas disease has been recently presented (Longinotti et al., 2011, Fig. 12) in which the biological sensitive element is immobilized onto the surface of silica-coated superparamagentic iron oxide nanoparticles. The use of nanoparticles reduces the incubation time to a few minutes, while an analog ELISA usually would require 30-60 minutes incubation. 


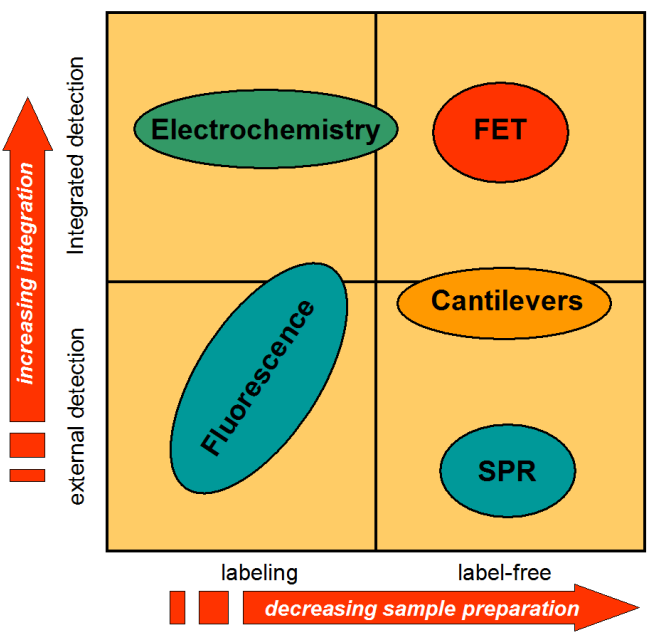

Fig. 11. Comparison of ease of sample preparation and integration for different transducers employed in immunosensors.

Finally, multiple analytes detection (Chen et al., 2009), microfluidics (Bange et al., 2005) and lab-on-a-chip (Hart et al., 2011) concepts are clearly in the future of immunosensors, and many devices have been presented that may also find soon wide application, with great impact in health care assessment, especially in developing countries.

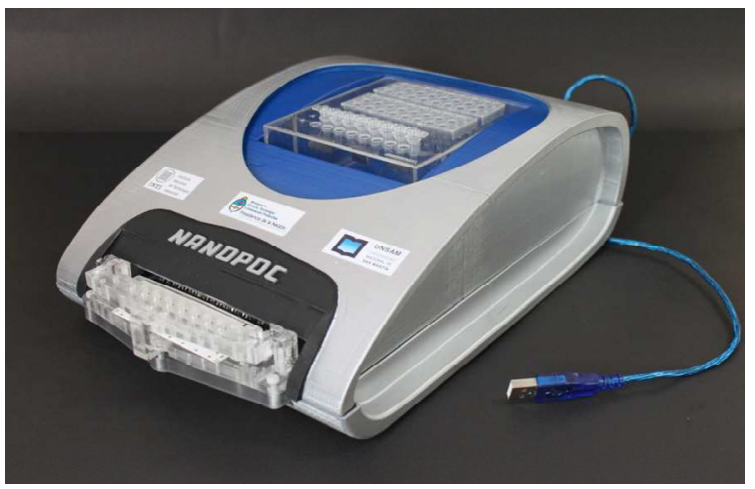

Fig. 12. Point of care electrochemical immunosensing platform Nanopoc ${ }^{\circledR}$, designed for the diagnosis of foot-and-mouth disease, brucellosis, and Chagas disease (Longinotti et al., 2011). The sample preparation is carried out in the blue sector, which involves magnetic separations. The final amperometric measurement is carried out in the 8-channel electrochemical cells at the front of the device. Data are processed by a PC via a USB connection.

\section{Conclusions}

The field of immunosensors is an exciting, fast growing one, as can be seen from the evolution of the number of scientific publications from 1990 to 2011 (Fig. 13). Especially, 
electrochemical immunosensors seem to lead the trend, possibly because of the ease of integration with electronic instrumentation, while optical and piezoelectric transducers are more demanding in this regard. However, due to the high sensitivity of optical and piezoelectric transducers, these kinds of transducers may soon find many practical applications. It is expected that the research in this field will continue to grow in the next years and point of care testing platforms will soon find wide applications that will greatly improve the health caring situation.

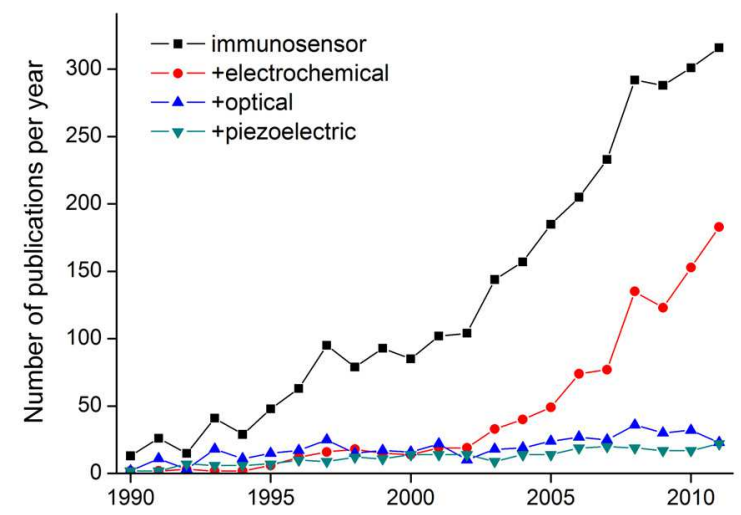

Fig. 13. Evolution of published articles on immunosensors (source: Scopus database).

\section{Acknowledgment}

This work has been supported by the Instituto Nacional de Tecnología Industrial and by FS Nano 005 granted by the Ministry of Science, Technology and Innovative Production of the Argentine Republic.

\section{References}

Bange, A.; Halsall, H.B. \& Heineman, W.R. 2005. Microfluidic immunosensor systems. Biosensors and Bioelectronics. Vol. 20, pp. 2488-2503.

Burg, T.P.; Godin, M.; Knudsen, S.M.; Shen, W.; Carlson, G.; Foster, J.S.; Babcock, K. \& Manalis, S.R. 2007. Weighing of biomolecules, single cells and single nanoparticles in fluid. Nature. Vol. 446, pp. 1066-1069.

Braun, T.; Barwich, V.; Ghatkesar, M.K.; Bredekamp, A.H.; Gerber, C.; Hegner, M. \& Lang, H.P. 2005. Micromechanical mass sensors for biomolecular detection in a physiological environment Physical Review E (Statistical, Nonlinear, and Soft Matter Physics). Vol. 72, pp. 031907.

Borisov, S.M. \& Wolfbeis, O.S. 2008. Optical Biosensors. Chem. Rev., Vol. 108, pp. 423-461.

Bromage, E.S.; Vadas, G.G.; Harvey, E.; Unger, M.A. \& Kaattari, S.L. 2007. Validation of an antibody-based biosensor for rapid quantification of 2,4,6-trinitrotoluene (TNT) contamination in ground water and river water. Environ. Sci. Technol., Vol. 41, pp. 7067-7072. 
Cash, K. J.; Ricci, F.; Plaxco, K.W. 2009. An electrochemical sensor for the detection of protein-small molecule interactions directly in serum and other complex matrices. J. Am. Chem. Soc. Vol. 131, pp. 6955-6957.

Chen, H.; Jiang, C.; Yu, C.; Zhang, S.; Liu, B. \& Kon, J. 2009. Protein chips and nanomaterials for application in tumor marker immunoassays. Biosensors and Bioelectronics. Vol. 24, pp. 3399-3411.

Fratamico, P.M., Strobaugh, T.P., Medina, M.B., Gehring, A.G. 1998. Detection of Escherichia coli O157:H7 using a surface plasmon resonance biosensor. Biotech. Tech. Vol. 12, pp. 571-576.

Fu, Z.; Yang, Z.; Tang, J.; Liu, H.; Yan, F.\& Ju, H. 2007. Channel and substrate zone twodimensional resolution for chemiluminescent multiplex immunoassay. Anal. Chem. Vol. 79, pp. 7376-7382.

Hart, R.W.; Mauk, MG; Liu, C.; Qiu, X; Thompson, J.A.; Chen, D.; Malamud, D.; Abrams, W.R. \& Bau, H.H. 2011. Point-of-care oral-based diagnostics. Oral Diseases. Vol. 17, pp. 745-75.

Hock, B. 1997. Antibodies for immunosensors. A review. Analytica Chimica Acta. Vol. 347 pp. 177-186.

Homola, J. 2003. Present and future of surface plasmon resonance biosensors. Anal. Bioanal. Chem. Vol. 377, pp. $528-539$.

Ivanoff Reyes, P.; Ku, C.-J.; Duan, Z.; Lu, Y.; Solanki, A. \& Lee, K.-B. 2011. ZnO thin film transistor immunosensor with high sensitivity and selectivity. App. Phys. Lett., Vol. 98, 173702.

Jacobs, C.B; Peairs, M.J. \& Venton, B.J. 2010. Review: Carbon nanotube based electrochemical sensors for biomolecules. Analytica Chimica Acta. Vol. 662, pp. 105127.

Janshoff, A.; Galla, H. \& Steinem, C. 2000. Piezoelectric mass-sensing devices as biosensors An alternative to optical biosensors? Angewandte Chemie - International Edition. Vol. 39, pp. 4004-4032.

Lazcka, O.; Del Campo, F.J. \& Muñoz, F.X. 2007. Pathogen detection: A perspective of traditional methods and biosensors. Biosens. Bioelec., Vol. 22, pp. 1205-1217.

Lee, J.H.; Kang, D.Y.; Lee, T.; Kim, S.U.; Oh, B.K. \& Choil, J.W. 2009. Signal enhancement of surface plasmon resonance based immunosensor using gold nanoparticle-antibody complex for $\beta$-amyloid (1-40) detection. J. Nanosci. Nanotechnol. Vol. 9, pp. 71557160 .

Leung, A.; Shankar, P. M. \& Mutharasan, R. 2007. A review of fiber-optic biosensors. Sensors and Actuators B. Vol. 125, pp. 688-703.

Lloret, P.; Longinotti, G.; Ybarra, G.; Socolovsky, L.; Halac, B. \& Moina, C. 2010. Synthesis, characterization, and functionalization of magnetic core-shell flower-like nanoparticles. Proc. XIX International Materials Research Congress, Cancún, México, August 15-19, 2010.

Longinotti, G.; Lloret, P.; Peter-Gauna, R.; Ybarra, G.; Ciochinni, A.; Hermida, L.; Malatto, L.; Fraigi, L. \& Moina, C. 2010b. Natural polymer coated magnetic nanoparticles for biosensing. Proceedings of the XIX International Materials Research Congress, Cancún, México, 15-19/8/2010.

Longinotti, G.; Ybarra, G.; Lloret, P.; Moina, C.; Ciochinni, A.; Hermida, L.; Milano, O.; Roberti, M.; Malatto, L. \& Fraigi, L. 2008. Screen-printed electrochemical biosensors 
based on magnetic core-shell nanoparticles, Proceedings of the 6th Ibero-American Congress on Sensors, November 24-26, 2008, São Paulo, Brazil.

Longinotti, G; Ybarra, G.; Lloret, P; Melli, L.; Rey Serantes, D.; Comerci, D.; Ciochinni, A.; Ugalde, J.; Moina, C.; Malatto, L; Mass, M.; Roberti M.; Brengi, D.; Tropea, S; Fraigi, L. \& Lloret, M. 2011. Point of care diagnosis of infectious diseases. INTI Spring Meeting, Buenos Aires, Argentina, October 2011.

Longinotti, G.; Ybarra, G.; Lloret, P.; Moina, C.; Ciochinni, A.; Rey Serantes, D.; Malatto, L.; Roberti, M.; Tropea, S. \& Fraigi, L. 2010a. Diagnosis of foot-and-mouth disease by an electrochemical enzyme-linked immunoassay. Proceedings of the 32nd Annual International Conference of the IEEE Engineering in Medicine and Biology Society "Merging Medical Humanism and Technology", Buenos Aires, Argentina, September 2010.

Melli, L. 2011. Development of optical and electrochemical immunosensors for the diagnosis of Chagas disease. Thesis. Universidad Nacional de Gral. San Martín.

Meyerhoff, M.E.; Duan, C. \& Meusel, M. 1995. Novel nonseparation sandwich-type electrochemical enzyme immunoassay system for detecting marker proteins in undiluted blood. Clin. Chem. Vol. 41, pp. 1378-1384.

Myszka, D.G. 2004. Analysis of small-molecule interactions using Biacore S51 technology. Anal. Biochem. Vol. 329, pp. 316.

Mullett, W.M.; Lai, E.P.C; Yeung, J.M. 2000. Surface plasmon resonance-based immunoassays. Methods. Vol. 22, pp. 77-91.

Ogert, R.A.; Brown, J.E.; Singh, B.R.; Shriverlake, L.C. \& Ligler, F.S. 1992. Detection of Clostridium botulinum toxin-A using a fiber optic-based biosensor. Anal. Biochem. Vol. 205, pp. 306-312.

Owino, J.H.O.; Ignaszak, A.; Al-Ahmed, A.; Baker, P.G.L.; Alemu, H.; Ngila, J.C. \& Iwuoha, E.I. 2007. Modelling of the impedimetric responses of an aflatoxin B1 immunosensor prepared on an electrosynthetic polyaniline platform. Anal. Bioanal. Chem. Vol. 388, pp. 1069.

Radke, S.M. \& Alocilja, E.C. 2005. A high density microelectrode array biosensor for detection of E. coli O157:H7. Biosens. Bioelectron. Vol. 20, pp. 1662-1667.

Raiteri, R.; Grattarola, M.; Butt, H.-J. \& Skládal, P. 2001. Micromechanical cantilever-based biosensors. Sens. Actuators B. Vol. 79, pp. 115-126.

Rusling, J.F., Sotzing, G. \& Papadimitrakopoulosa, F. 2009. Designing nanomaterialenhanced electrochemical immunosensors for cancer biomarker proteins. Bioelectrochemistry. Vol. 76, pp. 189-194.

Scaranoa, S.; Mascinia, M; Turnerb, A.P.F. \& Minunnia, M. 2010. Surface plasmon resonance imaging for affinity-based biosensors. Biosensors and Bioelectronics. Vol. 25, pp. 957966.

Skottrup, P.D.; Nicolaisen, M. \& Justesen A.F. 2008. Towards on-site pathogen detection using antibody-based sensors. Biosensors and Bioelectronics. Vol. 24, pp. 339-348.

$\mathrm{Su}$, X.-L. \& Li, Y. 2004. A self-assembled monolayer-based piezoelectric immunosensor for rapid detection of Escherichia coli O157:H7. Biosens. Bioelectron. Vol. 19, pp. 563-574.

Tokarskyy, O. \& Marshall, D.L. 2008. Immunosensors for rapid detection of Escherichia coli O157:H7 - Perspectives for use in the meat processing industry. Food Microbiology. Vol. 25, pp. 1-12. 
von Lode, P. 2005. Point-of-care immunotesting: Approaching the analytical performance of central laboratory methods. Clinical Biochemistry. Vol. 38, pp. 591 - 606.

Wee, K.W., Kang, G.Y., Park, J., Kang, J.Y., Yoon, D.S., Park, J.H., Kim, T.S. 2005. Novel electrical detection of label-free disease marker proteins using piezoresistive self-sensing micro-cantilevers. Biosens. Bioelectron. Vol. 20 , pp. 1932-1938.

Xiao, Y.; Lubin, A. A.; Heeger, A. J.; Plaxco, K. W. 2005. Label-free electronic detection of thrombin in blood serum by using an aptamer-based sensor. Angew. Chem., Int. Ed., Vol. 44, pp. 5456-5459.

Yimit, A.; Rossberg, A.G.; Amemiya, T. \& Itoh, K. 2005. Thin film composite optical waveguides for sensor applications: a review. Talanta. Vol. 65, pp. 1102-1109.

Yu, L.S.L.; Reed, S.A. \& Golden, M.H. 2002. Time-resolved fluorescence immunoassay for the detection of Escherichia coli O157:H7 in apple cider. J. Microbiol. Meth. Vol. 49, pp. 63-68. 


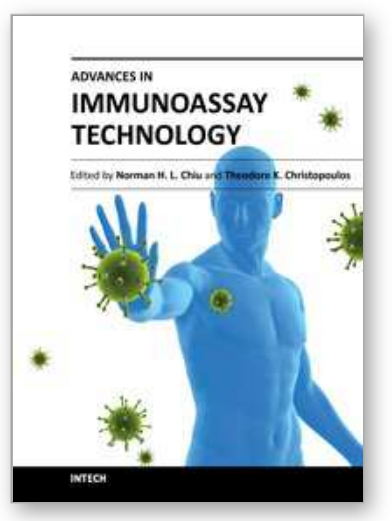

\author{
Advances in Immunoassay Technology \\ Edited by Dr. Norman H. L. Chiu
}

ISBN 978-953-51-0440-7

Hard cover, 180 pages

Publisher InTech

Published online 23, March, 2012

Published in print edition March, 2012

From the basic in vitro study of a specific biomolecule to the diagnosis or prognosis of a specific disease, one of the most widely used technology is immunoassays. By using a specific antibody to recognize the biomolecule of interest, relatively high specificity can be achieved by immunoassays, such that complex biofluids (e.g. serum, urine, etc.) can be analyzed directly. In addition to the binding specificity, the other key features of immunoassays include relatively high sensitivity for the detection of antibody-antigen complexes, and a wide dynamic range for quantitation. Over the past decade, the development and applications of immunoassays have continued to grow exponentially. This book focuses on some of the latest technologies for the development of new immunoassays.

\title{
How to reference
}

In order to correctly reference this scholarly work, feel free to copy and paste the following:

Carlos Moina and Gabriel Ybarra (2012). Fundamentals and Applications of Immunosensors, Advances in Immunoassay Technology, Dr. Norman H. L. Chiu (Ed.), ISBN: 978-953-51-0440-7, InTech, Available from: http://www.intechopen.com/books/advances-in-immunoassay-technology/fundamentals-and-applications-ofimmunosensors

\section{INTECH}

open science | open minds

\section{InTech Europe}

University Campus STeP Ri

Slavka Krautzeka 83/A

51000 Rijeka, Croatia

Phone: +385 (51) 770447

Fax: +385 (51) 686166

www.intechopen.com

\section{InTech China}

Unit 405, Office Block, Hotel Equatorial Shanghai

No.65, Yan An Road (West), Shanghai, 200040, China

中国上海市延安西路65号上海国际贵都大饭店办公楼 405 单元

Phone: +86-21-62489820

Fax: +86-21-62489821 
(C) 2012 The Author(s). Licensee IntechOpen. This is an open access article distributed under the terms of the Creative Commons Attribution 3.0 License, which permits unrestricted use, distribution, and reproduction in any medium, provided the original work is properly cited. 